\title{
Integration of Cervical Cancer Screening Services in the Routine Examinations Offered in the Kenyan Health Facilities: A Systematic Review
}

\author{
Florence Munoru*, Lucy Gitonga, Moses Muraya \\ Chuka University, Chuka, Kenya \\ Email: ^florencemunoru@gmail.com
}

How to cite this paper: Munoru, F., Gitonga, L. and Muraya, M. (2019) Integration of Cervical Cancer Screening Services in the Routine Examinations Offered in the Kenyan Health Facilities: A Systematic Review. Open Journal of Obstetrics and Gynecology, 9, 656-668.

https://doi.org/10.4236/ojog.2019.95065

Received: March 27, 2019

Accepted: May 18, 2019

Published: May 21, 2019

Copyright () 2019 by author(s) and Scientific Research Publishing Inc. This work is licensed under the Creative Commons Attribution International License (CC BY 4.0).

http://creativecommons.org/licenses/by/4.0/

(c) (i) Open Access

\begin{abstract}
Cervical cancer is the second most common cancer among women and the leading cause of deaths among women worldwide. In Kenya, uptake of screening services is at $3.2 \%$ below the targeted of $70 \%$. Therefore, there is need to study the factors that lead to low uptake of the screening services. One way of increasing the uptake of the screening services is its integration with other routine services, thus leading to a reduction in morbidity and mortality rates associated with the disease. The objective of this study was to review and examine the importance of integrating cervical cancer screening services in the routine examinations offered in the Kenyan health facilities. A retrospective study design was adopted by this study. The review of articles, journals, strategic plans was done from the year 2012 to 2017. Data sources included Medline, PMC, Library, Pubmed, Google scholar, cancer prevention plans and strategies. About 28 data sources were reviewed with $78.5 \%$ indicating that increased knowledge and creation of awareness on cervical cancer would greatly improve the utilization of the screening services. More than $87 \%$ of the information collected among published work in Kenya demonstrated that knowledge on importance cervical cancer screening is inadequate. The primary results of this study suggest that all women of reproductive age (WRA) should undergo cervical cancer screening as a routine service. An integration approach should be adopted, to enhance knowledge on cervical cancer and the importance of screening, causes, preventive and treatment options. The study recommends that, the Government of Kenya through the Ministry of health should include cervical cancer screening as a routine procedure for all WRA.
\end{abstract}




\section{Keywords}

Utilization of Cervical Cancer Screening Services, Factors Affecting Uptake, Integration of Routine Services, Health Education and Cervical Cancer Screening, Creation of Awareness on Cervical Cancer Screening

\section{Introduction}

Like in all types of cancers, cervical cancer puts great strain on the economy with far reaching implications, because the disease is expensive to treat once a diagnosis is made [1]. The worst hit is the low and middle income countries [2] due to the illiteracy and poverty levels among the populations amongst other factors. Globally, $5 \%-10 \%$ of all cancers are attributed to genetic defects and $90 \%-95 \%$ to environmental and lifestyle factors such as cigarette smoking, diet, alcohol and physical inactivity. Additionally, of all cancer-related deaths, almost 25\% $30 \%$ are due to tobacco; $30 \%-35 \%$ are linked to diet; about $15 \%-20 \%$ are due to infections; and the remaining percentage are due to other factors like radiation, stress, physical activity, environmental pollutants [1]. In the low and middle income countries, at least $25 \%$ of cancers are also caused by infectious agents including human papilloma virus which causes cancer of the cervix. These risk factors can be minimized so as to provide significant opportunity to decrease the incidence and burden of the disease. The burden of cancer at the macro and micro level is huge and this is compounded by a severely limited capacity of most low-income countries to provide the necessary health care [1]. In 2015, only 35\% of low-income countries reported having pathology services being available in the public sector. More than $90 \%$ of high-income countries reported treatment services are available compared to less than $30 \%$ of low-income countries [2].

Cervical cancer is the second most common cancer among women and also the leading cause of deaths among women worldwide. The world has a population of 2784 million women aged 15 years and older who are at risk of developing cervical cancer [3]. The disease has high mortality and morbidity rates, but if preventive and treatment measures are instituted early, the rates can be reduced drastically [4]. In a World health Organization [2] report, it was observed that although the world strives to fight poverty, illiteracy, and diseases, the increasing rates of cancer have put a great strain to the already outstretched health care systems in the world, and especially in the hard hit low and middle income countries. Communities and individuals are grappling with the challenge of a disease that is difficult to treat; but on the other hand, it's worth noting that most cancers can be prevented and some are treatable if detected early and especially the cancer of the cervix [2].

A report by the National Cancer Institute (NCI) indicates that an estimated 256,078 women were living with cancer in the United States in the year 2014, with 12,578 women having been diagnosed with cervical cancer and 4115 having 
died from the disease in the same period. Although the disease used to be the leading cause of cancer deaths for women in the United States, in the past 40 years, the numbers of cases and deaths have decreased significantly [4]. In Zimbabwe, 2270 women were diagnosed with cervical cancer annually and a mortality of $64 \%$ was recorded, with a high disease burden as a result of late presentation of disease. This has been attributed to poor screening and treatment options after being diagnosed with the disease [5]. In Zambia, about 2330 women have been diagnosed with cervical cancer and 1380 die yearly out of the disease, being a major cause of morbidity and mortality according to a human papilloma Virus (HPV) information report [6].

In Kenya, cervical cancer cases are estimated at 4802 and a mortality of about 2451 annually according to the Kenya Demographic Health Survey [7]. Cancer of the cervix ranks as the first leading cause of female cancer deaths in Kenya among women aged 15 to 44 years, at 3.2\% far from the expected $70 \%$ coverage despite a previous preventive strategic plan in place [8]. By the year 2012 there were approximately 10 to 15 new cases of cervical cancer in Nairobi each week according to the Kenya Cancer Registry [9]. Thus, it's evident that if no interventions are put in place the disease will claim more lives than estimated in years to come. With the new cancer prevention strategic plan being rolled out by Ministry of Health $(\mathrm{MOH})$, its success will be based on identifying and addressing the challenges experienced in the previous programs [1]. The development of cervical cancer takes some time with the cells developing into precancerous cells before progressing to true invasive cancer. If women access screening services at the stage of precancerous stage, then the progression of the disease can be arrested with a good prognosis since this stage of cervical cancer is curable. One of the most associated causes of cervical cancer development is the Human Papilloma Virus (HPV) which contributes to over 50\% of all diagnosed cases [10].

Despite much research, formulation of policies, guidelines and strategies that have been done concerning cervical cancer disease and screening services, there is still inadequate knowledge, lack of awareness and poor uptake of screening service. There are two most commonly recommended tests, i.e., Pap smear test [4] and visual screening test. The visual screening approaches are relatively simple and low-cost, and rely on little infrastructure. Health providers can perform the procedures comfortably at the local settings, provided that they receive adequate training. Also the results of the procedures are available immediately, making it possible, in principle, to offer treatment or referral options during the same visit [8]. Hence, they can easily be integrated with routine examination in any given health facility. The objective of this study was to interrogate the importance of integrating cervical cancer screening services in the routine examinations offered in the Kenyan health facilities. The study aimed at identifying the probable causes and solutions to the low uptake of cancer screening services and the attempt to address them in order to improve the uptake of the services. 


\section{Methodology}

A retrospective study design was adopted by this study which was done by reviewing of articles, journals, strategic plans and policies from the year 2012 to 2017. This design was adopted to facilitate a broad understanding as to why after years of research, strategic planning and formulation of policies, the uptake of cervical cancer screening services have remained low.

\subsection{Search Strategy for Identification of Studies}

Data sources included Medline, PMC, Library, PubMed, Google scholar, cancer prevention plans and strategies. The key words searched were cervical cancer screening services, uptake of cervical cancer services, factors affecting cervical cancer screening services utilization. Only articles which were discussing cervical cancer screening services uptake were considered.

Type of literature which was considered relevant for adoption were those which attributed knowledge and creation of awareness as key factors to poor uptake of cervical cancer screening services. This is because most research in the third world countries and especially the low income Countries suggested so.

\subsection{Data Collection and Analysis}

Articles and journals search was done in the internet, policy documents and strategic plans were retrieved from the library. Titles, abstracts, results, conclusions and recommendations were screened for potential relevance and full texts for inclusion. The studies were divided into those which indicated or concluded that there was a knowledge gap on cervical cancer and those which indicated that there was need to create awareness on cervical cancer disease and screening approaches. Published journals, articles, plans and strategies from Kenya were included to capture the local situation. Literature reviewed was from the year 2011 to 2017 since it includes most recent research and is more reliable when capturing the local situation. All data sources were not included because most had similar findings or were not legible. The literature that had the key words was considered for review and especially from Kenya and other the low income countries. Once the data was accessed, reviews were made and entries madeas shown in Figure 1.

\section{Results}

The search yielded 97 published articles and 5 other sources which included strategic plans, guidelines and protocols. After the duplicate publications were removed, 41 remained and screening was done. After screening the study titles and their abstracts, 30 were found to be potentially relevant and 11 didn't meet the criteria for further review. After completing the full text review 28 were found eligible for inclusion in the study, 22 were found to be having the key phrases of lack/low knowledge levels and lack/inadequate awareness on the cervical cancer disease and its screening approaches. Only 6 of the reviewed sources 
had different results and conclusions as shown in Figure 1.

Out of 28 data sources which were reviewed, 22 (78.5\%) indicated that increased knowledge and creation of awareness on cervical cancer would greatly improve the utilization of the screening services. Research carried out in Nyeri, Vihiga, Mombasa, Eldoret, Embu, Nairobi and Kisumu which are Kenyan towns reveal that, more than $87 \%$ of the information collected among published work in Kenya demonstrated that knowledge on importance cervical cancer screening is inadequate (Table 1). The researchers reiterated that there was low uptake of the screening services for cervical cancer and that creation of awareness was very necessary. The results of this study suggest that all women of reproductive age (WRA) should undergo cervical cancer screening as a routine service thus scaling up knowledge on the disease severity and what services are available. An integration approach should be adopted; to enhance knowledge on cervical cancer and the importance of screening, causes, preventive and treatment options and other interventions pertaining to the disease. Even if the client opts out of being screened with the health provider having given health education and recommending the test, she will leave the facility as a knowledgeable and empowered individual, just the way it happens with HIV testing and other communicable diseases. Provision of health education and creation of awareness are key component in primary health care whose importance needs to be emphasised.

Table 1. Data sources.

\begin{tabular}{|c|c|c|c|c|}
\hline Data source and Title & Author & $\begin{array}{l}\text { Year of } \\
\text { Publication }\end{array}$ & $\begin{array}{l}\text { Findings/ factors affecting uptakel conclusions/ } \\
\text { Recommendations }\end{array}$ & $\begin{array}{l}\text { Relevance } \\
\text { / comment }\end{array}$ \\
\hline $\begin{array}{l}\text { Raising public awareness and cancer } \\
\text { advocacy at the community level }\end{array}$ & [20] & 2017 & $\begin{array}{l}\text { Diagnosis is made at a late stage due to late } \\
\text { presentation at the facility. }\end{array}$ & $\begin{array}{l}\text { Not relevant- } \\
\text { emphasis on } \\
\text { more research }\end{array}$ \\
\hline $\begin{array}{l}\text { Factors influencing uptake of screening } \\
\text { cervical cancer among women of child } \\
\text { bearing age in Vihiga County Kenya. }\end{array}$ & [14] & 2015 & $\begin{array}{l}\text { - Lack of available outreach programmes } 63.3 \% \\
\text { - Sensitization and education on existence and } \\
\text { severity of cervical cancer. } \\
\text { - Integration of screening services in the routine } \\
\text { examinations } \\
\text { - Religious and cultural beliefs }\end{array}$ & Relevant \\
\hline $\begin{array}{l}\text { Kenya National Cervical Cancer } \\
\text { Prevention Program: Strategic Plan } \\
\text { 2012-2015 }\end{array}$ & [8] & 2012 & $\begin{array}{l}\text { strategic areas for improvement included } \\
\text { - Creation of awareness } \\
\text { - Conduct mass campaigns } \\
\text { - Empower health providers } \\
\text { - Multi-sectoral collaboration }\end{array}$ & Relevant \\
\hline $\begin{array}{l}\text { Determinants of Cervical Screening } \\
\text { Services Uptake, among } 18 \text { - } 49 \text {-year-old } \\
\text { Women Seeking services at the } \\
\text { Jaramogi Oginga Odinga Teaching and } \\
\text { Referral Hospital, Kisumu, Kenya. }\end{array}$ & {$[33]$} & 2014 & $\begin{array}{l}\text { - Self-reporting examinations } \\
\text { - Increasing knowledge } \\
\text { - Enhance health education } \\
\text { - Provide free services }\end{array}$ & Relevant \\
\hline $\begin{array}{l}\text { Factors affecting cervical cancer } \\
\text { diagnosis and treatment in selected } \\
\text { hospitals in the Mombasa County, } \\
\text { Kenya }\end{array}$ & [21] & 2013 & $\begin{array}{l}\text { - } 63.4 \% \text { not aware of causes of cervical cancer } \\
\text { - Inadequate knowledge } \\
\text { - Government to initiate awareness programs } \\
\text { - Upgrade facilities to offer treatment and care }\end{array}$ & Relevant \\
\hline
\end{tabular}




\section{Continued}

National Cancer Control Prevention programme

2017

Cancer Control Knowledge into Action-WHO Guide for Effective programs: Module 3.

Utilization of cervical cancer screening services and its associated factors among primary school teachers, Dar es Salam,

Tanzania

Perceptions of risk and barriers to cervical screening at Moi Teaching and referral Hospital (MTRH), Eldoret, Kenya.

Improving access to Cancer Testing and treatment in Kenya

Awareness, perception and factors affecting utilization cancer of the cervical screening services among women in Ibadal, Nigeria.

The Acceptability of Vaginal Smear Self-Collection for Screening for Cervical [26] Cancer; a Systemic Review Clinics

Multiple human papilloma virus infections and HIV seropositivity as risk factors for abnormal cervical cytology, among female ${ }^{[10]}$ sex workers in Nairobi.

Factors influencing utilization of cervical cancer screening services in Embu hospital, Kenya

Uptake of cervical cancer screening among HIV positive women in Comprehensive care Centre Nairobi Kenya
- Raise public awareness among the youth and other vulnerable groups

- Improve human resource

Relevant

- Health education on lifestyle change

- Emphasis on creation of awareness on all diseases because this is the pivot point of primary health care.

- There is need to upscale health education and

Relevant creation of awareness among the populations

- Low utilization of services

- Support from spouse lacking

- $96 \%$ never went for screening

- $32 \%$ don't know cervical cancer is preventable

- Previous exposure to reproductive Health services associated with higher awareness

- Individual characteristics e.g. age determine whether a Relevant woman will go for services.

- Knowledge of risk factors influenced uptake

- High cost of treatment after diagnosis

- Low levels of knowledge

- Poor health seeking behaviour

- Increase public awareness

Relevant

- Implement policies.

- Improve health insurance

Indicators of lack of awareness include

- Late reporting to hospital for treatment, diagnosis.

- Ignorance

- Cultural issues

Relevant

- Urgent need for more enlightenment about cervical cancer especially by health workers.

- Should be part of Ante natal clinic education

- Self vaginal smear collection was a well-accepted method that would increase in participation in cervical cancer screening.

Relevant

- Embarrassment during screening

- Improve Health education and awareness

Being seroreactive was a risk factor to developing cervical cancer

Not relevant

- $59 \%$ doesn't know of any cervical cancer screening tests.

- $36 \%$ have undertaken a test.

- $78 \%$ don't know the risk factors associated with

Relevant cervical cancer.

- $76 \%$ lack information about cervical cancer.

- There was access to information to services,

- Adequate knowledge on cervical cancer and screening for the deadly disease.
Not in agreement with knowledge and awareness gap 


\section{Continued}

Factors influencing cervical cancer screening in a Kenyan health facility

Effects on cervical cancer education and provider recommendation for screening on screening rates

Seeking, Delaying and Avoiding Routine Health Care Services.

Cervical Cancer Statistics (Reviewed 2017) HPV-Associated Cervical Cancer Rates by [16] Race and Ethnicity.

Assessment of Community Health Volunteers' Knowledge on Cervical Cancer in Kadibo Division, Kisumu County

Cervical Cancer Screening, Behavior of Zimbabwean Women. Journal of Women's Health

International Journal for Cancer Incidence and mortality worldwide; sources and, methods and major patterns. GLOBOCAN 2012.

Prevalence and risk factors associated with precancerous cervical cancer lesions among HIV-infected women in resource-limited setting (Kenya)

Nurses Perceptions about Reasons for Women's Non-Utilisation of Cervical Cancer Screening Services in Malawi.

Factors influencing uptake of Cervical Cancer Screening among women in India

Factors influencing utilization of cervical cancer screening services at central provincial general hospital, Nyeri, Kenya

Knowledge, Attitude and Practice for Cervical Cancer Prevention and Control among Women of Childbearing Age in Hossana Town, Hadiya zone, Southern Ethiopia
- Fear of pain and intrusive procedure

- Long waiting time

- Service provider barriers especially male nurses offering service to female clients

- Telephone reminders can help improve uptake

- Provider initiation improves uptake of services

- Integration of cervical cancer screening services

- Increase knowledge and awareness

- Scale up cervical cancer screening and treatment urgently

- Integrated cervical cancer prevention, screening and treatment approach is needed.

- More black women get Human Papilloma virus associated vaginal cancer than other races

No actual knowledge gap identified

Relevant

Relevant

Not relevant

- There was low knowledge of the risk factors of cervical cancer

- Health education

Relevant

- Creation of awareness

- Improve access to screening service

- Incorporate the Human Papilloma Virus vaccine in the immunization schedule

- Intensify health education

- Cancer of the cervix has declined in importance

- Is common in less developed regions

- Is the most common cancer in women in Eastern and Middle Africa

- Availability and accessibility of screening services be done through integration with HIV care.

- Regular screening of HIV women should be

Not relevant paramount

- Shortage of midwifes to perform the screening services

- Inadequate health education

- Unfavourable screening schedules

Relevant

- Geographical distances from services

- Low knowledge among the participants regarding cervical cancer and Pap smear screening

- most people don't undergo routine check ups

Relevant

- older women were custodians of knowledge

- Low levels of awareness on issues relating to cervical cancer screening.

- Some women see cervical cancer screening as a curative ${ }_{\text {Relevant }}$ measure rather than a preventive measure.

- health education programs are necessary

- Importance of awareness creation,

- Increasing knowledge,

- Promoting active searching for health information and experiences of receiving information from any Relevant

- Integrate cervical cancer prevention strategies with other reproductive health services at all level of health care delivery system. 


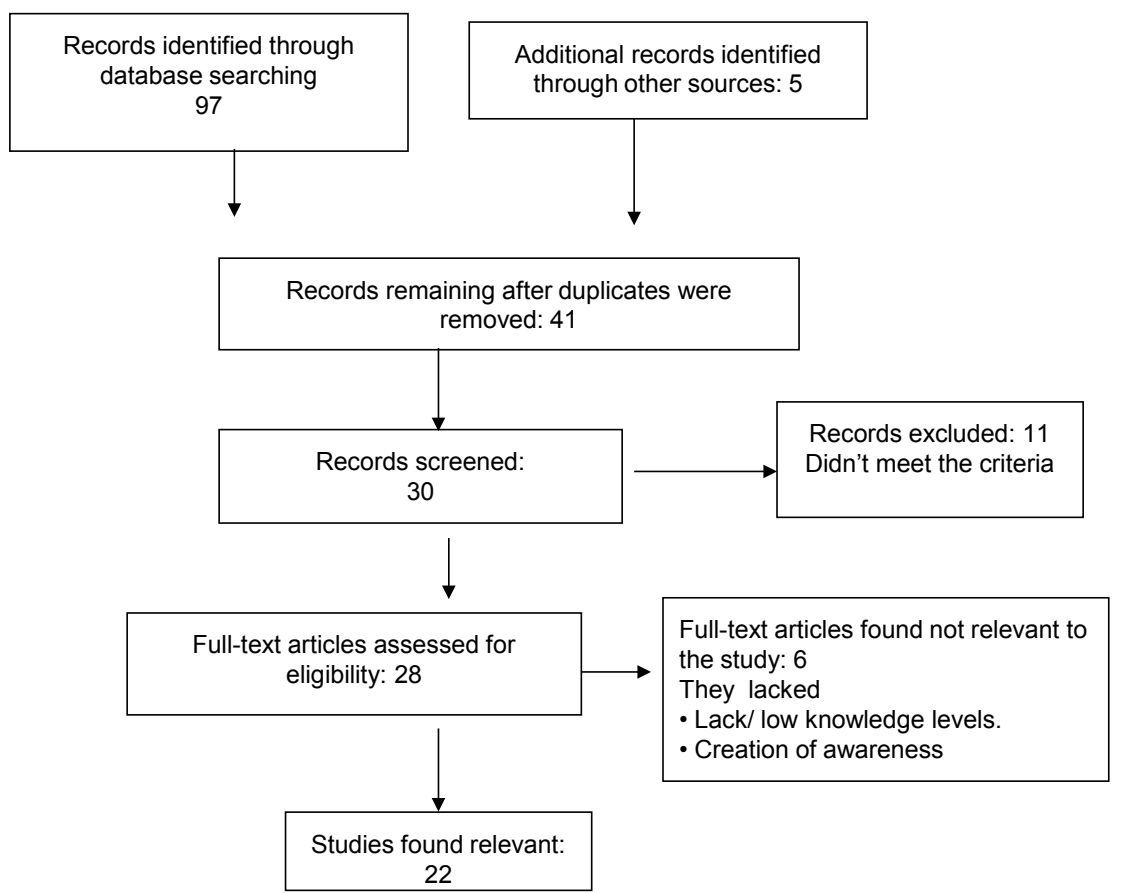

Figure 1. PRISMA flow diagram.

\section{Discussion}

The findings of this study are consistent with a Cochrane review reported by Musa et al. (2017) which found out that invitation letters and telephone reminders greatly improved uptake of cervical cancer screening services. They reiterated that education on cervical cancer and provider initiated screening had significant impact on improvement of the uptake of the services [11]. The Kenya cancer prevention strategic plan of 2017 to 2022 points at creation of awareness as one factor of improving uptake of cancer screening services which is in agreement with the finding [1].

Lack of adequate knowledge on the disease can be greatly improved if WRA were given an opportunity to get education on the cervical cancer disease. At every hospital visit made, health education on causes, prevention, screening services available, treatment options and other interventions pertaining to the disease should be given and an opportunity provided for screening. Even if the client opts out of being screened for cervical cancer, she will leave the facility as a knowledgeable and empowered individual just the way it happens with HIV testing. More than $87 \%$ of the information collected among published work in Kenya demonstrated that knowledge on importance cervical cancer screening is inadequate. Most Research carried out in Kenya recommended that the screening services be integrated with other routine services. Kibicho (2014) recommended intensifying of mass education on risk factors for diseases, cervical cancer screening to be incorporated into $\mathrm{MCH} / \mathrm{FP}$ services programme to create awareness of cervical cancer [12]. In a contrary finding, studies carried out in Nairobi found out that there was adequate knowledge and awareness concerning 
cervical cancer screening and on the disease among women who were attending Comprehensive Care clinic (CCC) for the HIV/AIDS patients [13]. This study disagrees with other studies carried out in Kenya which revealed that there was a knowledge gap.

There is a possibility that the clients who attended the comprehensive care were given health education on cervical cancer disease because they were on follow up care. Therefore this supports the basis for adequate knowledge base and awareness on the cervical cancer disease among the women attending CCC. This would greatly justify the importance of health education as a major influence to the improvement of the screening services. It's important to note that all women found to be HIV positive are routinely given health education and screened for cervical cancer in the Kenyan health facilities.

Other findings revealed that distance from facilities, embarrassment during examination, long waiting time before being attended are causes associated with low uptake of cervical cancer screening services which also featured in the results.

\subsection{Lack of Knowledge on Cervical Cancer Disease and Availability of Cervical Cancer Screening Services}

When individuals understand the severity of a disease like cervical cancer which includes its causes, risk factors preventive measures, treatment options and where to seek help, there is a high likelihood that their health seeking behaviour will improve [14]. A study carried out on factors influencing uptake of Cervical Cancer Screening among women in India revealed that knowledge was low among the participants regarding cervical cancer and Pap smear screening [15]. In a recent reviewed study by the Centre for Disease Control and prevention (CDC), it was found out that in the year 2014, black women had the highest rate of cervical cancer deaths followed by Hispanic, White, Asian/Pacific Islander and American Indian/Alaska [16] as a result of in adequate knowledge on the disease and genetic predisposition.

The disease trends was largely associated with poor knowledge, inaccessible health facilities, cost factors in follow up of confirmed cases, and discomfort during examination [14]. The same results were recorded in Ethiopia and similar findings concurred with the research done in Zimbambwe [17]. In sub-Saharan African countries disease screening is not routine, also in the African tradition, people do not access health-care check-ups or screening because the concept of a check-up is not known and is not common practice, instead people tend to access healthcare services when they have disease symptoms [14].

\subsection{Lack of Awareness on the Severity of Cervical Cancer Disease and the Management Approaches}

Other communicable diseases like HIV, diabetes, TB and other diseases have been receiving media publicity thereby creating awareness to inform the populations that such diseases exists. With cervical cancer and the screening ap- 
proaches, nothing of the sort has been happening despite much research, strategic plans, policies and guidelines having been formulated. In a study carried out in Nyeri, it was found out that among other factors like lack of knowledge and awareness, lack of female screeners, embarrassment during examination and attitude of workers had some role to play in how clients utilized the services [18]. Since health education is given routinely before any examination or procedure is performed in the health facilities, then creation of awareness and dissemination of knowledge will have taken place for all women visiting the facilities [11] which in return improves uptake. Considering that WRA seek health services for various reasons like Antenatal care, family planning, Child welfare clinic, post natal services among others, then the provision of health education and awareness creation would be very productive if provided at every contact with the WRA.

\subsection{Integration of Cervical Cancer Screening Services in the Routine Examinations}

Whenever individuals visit health facilities and they are given health education on a regular basis, the individual leaves the health facility empowered and knowledgeable [19] reiterated that if cervical cancer screening services were to be improved, then integration of the service with the other routine services was necessary and especially on the preventive and treatment approach [19], the same recommendations were made by [17]. Once services are integrated with other routine examinations like blood sugar testing, Screening for HIV, blood pressure checking, breast examination among other tests, it becomes easier for the women since they will not need to come to the facility on another day for the service. This would be cost effective in terms of money and time. Since health education is given routinely before any examination or procedure is performed in the health facilities, then creation of awareness and dissemination of knowledge will have taken place for all women visiting the facilities [11] thereby increasing their knowledge on the disease and creating awareness at the same time.

\subsection{Limitations of the Study}

Most of the studies reviewed were those which had lack of or inadequate levels of knowledge and creation of awareness as factors that contributed to low uptake of cervical cancer screening services. It's worth noting that there were other factors that affect the uptake of the service like embarrassment and discomfort during examinations, religion and cultural beliefs among others. Most of these other factors would be addressed by health education and creation of awareness therefore great emphasis was not put on the other factors.

The study was more restrictive to the local situation and especially Kenya and other low income countries. A comparative study on the western countries would have yielded a broader understanding of how successful the service provision is in other populations. 


\section{Conclusion}

The findings contribute to the literature supporting creation of awareness and increase in knowledge through education as key factors in the improvement of uptake of cervical cancer screening services. This can be addressed by integrating the cervical cancer screening services in the routine examinations offered in the health facilities just like the way it's done for other non-communicable diseases e.g. HIV. In view of the above findings from Kenya and other parts of the world, the study recommends that the Government of Kenya through the Ministry of health should include cervical cancer screening as a routine procedure for all WRA. The integration of the service with other services is a sure way of eradicating lack of knowledge and also a way of creating awareness which are direct ways of addressing the low uptake.

\section{Recommendations}

In view of the above finding from Kenya and other parts of the world, the study recommends that the Government of Kenya through the Ministry of health should include cervical cancer screening as a routine procedure for all WRA.

\section{Conflicts of Interest}

The authors declare no conflicts of interest regarding the publication of this paper.

\section{References}

[1] Ministry of Health Kenya (2017) Kenya National Cancer Control Strategy 2017-2022.

[2] World Health Organization (2017) Cancer Control Knowledge into Action-WHO Guide for Effective Programs: Module 3.

[3] Bruni, L., Barrionuevo-Rosas, L., Albero, G. and Serrano, B. (2017) Information Centre on HPV and Cancer (HPV Information Centre). Human Papillomavirus and Related Diseases in the World.

[4] National Cancer Institute (2017) SEER Cancer Statistics Review 1975-2014. https://seer.cancer.gov.csr/1975-2014

[5] Kuguyo, O., Matimba, A., Tsikai, N., Magwali, T., Madziyire, M., Gidiri, M., Dandara, C. and Nhachi, C. (2018) Cervical Cancer in Zimbabwe. Pan African Medical Journal, 27, 215.

[6] Human Papilloma Virus and Related Cancers Fact Sheet (2017) ICO/IARC Information Centre on HPV and Cancer. https://www.hpvcentre.net

[7] Kenya Demographic and Health Survey (2014) Exploring Kenya's Inequality; Pulling Apart or Pooling Together. Kenya National Bureau of Statistics (KNBS).

[8] Ministry of Health Kenya (2012) Kenya National Cervical Cancer Control Strategic Plan 2012-2015.

[9] Kivuti, L., Roudsari, A., Pokhariyal, P. and McDonnell, G. (2012) Self-Reported Use of Internet by Cervical Cancer Clients in Two National Referral Hospitals in Kenya. BMC Research Notes, 5, 559.

http://www.biomedcentral.com/1756-0500/5/559 
https://doi.org/10.1186/1756-0500-5-559

[10] Patel, S., Mugo, N., Cohen, C. and Ting, J. (2013) Multiple Human Papillomavirus Infections and HIV Sero positivity as Risk Factors for Abnormal Cervical Cytology among Female Sex Workers in Nairobi. International Journal of STD \& AIDS, 24, 221-225. https://doi.org/10.1177/0956462412472446

[11] Musa, J., Achenbach, C.J., O’Dwyer, L.C., Evans, C.T., McHugh, M., et al. (2017) Effect of Cervical Cancer Education and Provider Recommendation for Screening on Screening Rates: A Systemic Review and Meta-Analysis. PLoS ONE, 12, e0190661. https://doi.org/10.1371/journal.pone.0183924

[12] Jedidah, K. (2014) Factors Influencing Utilization of Cervical Cancer Screening Services in Embu Hospital, Kenya. University of Nairobi Kenya.

[13] Lukarito, J., Wagoro, A. and Kimani, H. (2017) Uptake of Cervical Cancer Screening among HIV Positive Women in Comprehensive Care Centre Nairobi Kenya. Kenyatta University.

[14] Allan, I.M. (2015) Factors Influencing Uptake of Screening Cervical Cancer among Women of Child Bearing Age in Vihiga County, Kenya. Nairobi University.

[15] Singh, E., Shikkha, S., Vidya, R. and Dhiraj, K. (2002) Awareness of Cervical Cancer Screening among Nursing Staff in The United States Cancer Statistics: 1999-2014 Incidence and Mortality Web-Based Report. Department of Health and Human Services. Atlanta, GA. http://www.cdc.gov/uscsrtiary

[16] Centres for Disease Control and Prevention (CDC) and National Cancer Institute (2016 and 2017) Cancer Data and Reports.

[17] Aweke, Y.H., Ayanto, S.Y. and Ersado, T.L. (2017) Knowledge, Attitude and Practice for Cervical Cancer Prevention and Control among Women of Childbearing Age in Hossana Town, Hadiya Zone, Southern Ethiopia: Community-Based Cross-Sectional Study. PLOS ONE, 12, e0181415. https://doi.org/10.1371/journal.pone.0181415

[18] Gichogo, A.W. (2012) Factors Influencing Utilization of Cervical Cancer Screening Services at Central Provincial General Hospital, Nyeri, Kenya.

[19] Carla, G.A., Johnson, K.M. and Yarborough, B.J.H. (2014) Seeking, Delaying and Avoiding Routine Health Care Services. American Journal of Health Promotion, 28, 286-293. https://doi.org/10.4278/ajhp.120702-QUAL-318

[20] Siegel, R.L., Miller, K.D. and Jemal, A. (2017) Cancer Statistics, 2017. CA: A Cancer Journal for Clinicians, 67, 7-30. https://doi.org/10.3322/caac.21387

[21] Salesa, O.M. (2013) Factors Affecting Cervical Cancer Diagnosis and Treatment at Selected Public Hospitals in the Mombasa County.

http://erepository.uonbi.ac.ke/handle/11295/63458

[22] Kileo, N., Michael, D., Neke, N.M. and Moshiro, C. (2015) Utilization of Cervical Cancer Screening Services and Its Associated Factors among Primary School Teachers, Dar es Salam, Tanzania. BMC Health Services Research, 15, 552. https://doi.org/10.1186/s12913-015-1206-4

[23] Were, E., Nyaberi, Z. and Boziba, N. (2011) Perceptions of Risk and Barriers to Cervical Cancer Screening at Moi Teaching and Referral Hospital (MTRH), Eldoret, Kenya. African Health Sciences, 11, 58-64.

[24] Makau, K., Sandra, B., Greene, N. and Otieno, A. (2017) Improving Access to Cancer Testing and Treatment in Kenya. Journal of Global Oncology, No. 4, 1-8.

[25] Millicent, C. and Abosede, B. (2012) Awareness, Perception and Factors Affecting Utilization Affecting Cervical Cancer Screening Services among Women in Ibadaar Nigeria, a Qualitative Study. Reproductive Health, 9, 11. 
https://doi.org/10.1186/1742-4755-9-11

[26] Braz, N., Lorenzi. N., Sorpreso, I. and Aguiar, L. (2017) The Acceptability of Vaginal Smear Self-Collection for Screening for Cervical Cancer: A Systemic Review Clinics, 72, 183. https://doi.org/10.6061/clinics/2017(03)09

[27] Njuguna, E., Ilovi, S., Muiruri, P. and Mutai, K. (2017) Factors Influencing Cervical Cancer Screening in a Kenyan Health Facility: A Mixed Qualitative and Quantitative Study. International Journal of Reproduction, Contraception, Obstetrics and Gynecology, 6, 1180-1185. https://doi.org/10.18203/2320-1770.ijrcog20171381

[28] Ochomo, E., Atieli, H., Gumo, S. and Ouma, C. (2017) Assessment of Community Health Volunteers' Knowledge on Cervical Cancer in Kadibo Division, Kisumu County: A Cross Sectional Survey. BMC Health Services Research, 17, 675. https://doi.org/10.1186/s12913-017-2593-5

[29] Mupepi, S., Carolyn, M., Timothy, R. and Johnson, M. (2011) Knowledge, Attitudes, and Demographic Factors Influencing Cervical Cancer Screening Behaviour of Zimbabwean Women. Journal of Women's Health, 20, No. 6. https://doi.org/10.1089/jwh.2010.2062

[30] Ferlay, J., Soerjomataram, I., Dickshit, R., Eser, S., et al. (2015) Cancer Incidence and Mortality Worldwide: Sources, Methods and Major Patterns in GLOBOCAN 2012. International Journal of Cancer, 136, E359-E386. https://doi.org/10.1002/ijc.29210

[31] Memiah, P., Mbuthia, W., Kiiru, G., et al. (2012) Prevalence and Risk Factors Associated with Precancerous Cervical Cancer Lesions among HIV-Infected Women in Resource-Limited Setting. AIDS Research and Treatment, 2012, Article ID: 953743. https://doi.org/10.1155/2012/953743

[32] Hami, M., Ehlers, V.J. and van der Wal, D.M. (2015) Nurses Perceptions about Reasons for Women's Non-Utilisation of Cervical Cancer Screening Services in Malawi. Journal of Women's Health Care, 4, 240. https://doi.org/10.4172/2167-0420.1000240

[33] Morema, E., Atieli, H., Onyango, R., Omondi, J. and Ouma, C. (2014) Determinants of Cervical Screening Services Uptake among 18-49 Year Old Women Seeking Services at the Jaramogi Oginga Odinga Teaching and Referral Hospital, Kisumu, Kenya. BMC Health Services Research, 14, 335. https://doi.org/10.1186/1472-6963-14-335 